Sharif University of Technology
Scientia Iranica
Transactions A: Civil Engineering
SCIENTIA
IRAN I CA

\title{
A three-dimensional peano series solution for the vibration of functionally graded piezoelectric laminates in cylindrical bending
}

\author{
M. Lezgy-Nazargah* \\ Faculty of Civil Engineering, Hakim Sabzevari University, Sabzevar, P.O. Box 9617976487, Iran.
}

Received 21 August 2014; received in revised form 30 June 2015; accepted 7 October 2015

\section{KEYWORDS \\ Vibration analysis; \\ Peano series solution; State-space approach; Functionally graded piezoelectric materials.}

\begin{abstract}
The available three-dimensional (3D) solutions reported for the analysis of Functionally Graded Piezoelectric (FGP) laminates are based on this simplifying assumption that the FGP layer consists of a number of homogeneous sub-layers. The accuracy of these formulations not only is dependent on the number of sub-layers, but also leads to inaccurate results in the prediction of higher natural frequencies of the FGP laminates. In the present paper, a 3D Peano series solution is developed for the cylindrical bending vibration of the FGP laminates. This novel formulation exactly satisfies the equations of motion, the charge equation, and the boundary and interface conditions of the continuously nonhomogeneous piezoelectric layers. The obtained solution is exact because no a priori assumption for the displacement components and the electric potential along the thickness direction of FGP layers is introduced. The influences of the different functionally gradient material properties and different electric boundary conditions on the natural frequencies and mode shapes of the FGP laminate have also been studied through examples. The present solution and its obtained numerical results can be employed to assess the accuracy of different FGP laminated beam/plate theories. It can also be used for FGP vibration behavior comprehension purposes.
\end{abstract}

(C) 2016 Sharif University of Technology. All rights reserved.

\section{Introduction}

Behaviors of the laminated piezoelectric structures have been of intense research interests for more than two decades [1]. Various studies are available in the open literature which deal with the prediction of static and dynamic behaviors of piezoelectric laminated composite structures as well as their effective electromechanical properties [1-13]. The conventional piezoelectric devices are made of several layers of different piezoelectric materials. Although this conventional type of design may provide larger deformations, it

*. Tel.: +98 5744012784; Fax: +98 57440127771

E-mail addresses: m.lezgy@hsu.ac.ir and

m.lezgy@yahoo.com has several restricting disadvantages that reduce its reliability. For the piezoelectric actuators made of different piezoelectric layers or identical piezoelectric layers with different poling directions, high stress concentrations usually appear in the layer interfaces under mechanical or electrical loading [14]. These stress concentrations lead to the initiation and propagation of micro-cracks near the interfaces of two bonded piezoelectric layers [15]. The lifetime and the reliability of these structures significantly reduce with the aforementioned drawbacks. In order to overcome the performance limitations of the traditional layered piezoelectric elements, the concept of functionally graded piezoelectric sensors and actuators emerged [1617]. Functionally graded piezoelectrics are microscopically heterogeneous materials attributed by a smooth 
and continuous variation in mechanical and electrical properties along any/all directions in the reference coordinate system. Functionally graded piezoelectric actuators can not only produce large displacements but also reduce the internal stress concentrations and consequently improve the lifetime of piezoelectric actuators, significantly [14]. It is obvious that functionally graded sensors and actuators will have a significant function in the field of smart materials and structures. Research on static and/or dynamic behavior of FGP structures has been carried out by many researchers and various mathematical models have been developed until now. These mathematical models can be classified into two broad categories including two-dimensional (2D) models and three-dimensional (3D) models. In the following two paragraphs, these groups have been adequately reviewed.

In $2 \mathrm{D}$ models, the variations of the displacement components and the electric potential in the transverse direction of FGP structures are prescribed [7]. This idea is the origin of all of the beam/plate/shell theories presented for the analysis of these types of structures. Yang and Xiang [18] investigated the static and dynamic responses of FGP actuators under thermoelectro-mechanical loadings by using the Timoshenko beam theory. In their work, the numerical results were obtained by using the Differential Quadrature Method (DQM). A comprehensive study on the static, dynamic, and free vibration responses of FGP panels under different sets of mechanical, thermal, and electrical loadings using the finite element method was presented by Behjat et al. [19]. They obtained the governing equations using potential energy and Hamilton's principle based on the first-order shear deformation theory that includes thermo-piezoelectric effects. Behjat et al. [20] also investigated the static bending, free vibration, and dynamic response of FGP plates under mechanical and electrical loads using the first-order shear deformation theory. Wu et al. [21] derived a high-order theory for FGP shells based on the generalized Hamilton's principle. Doroushi et al. [13] studied the free and forced vibration characteristics of an FGP beam under thermo-electro-mechanical loads using the higher-order shear deformation theory. Lezgy-Nazargah et al. [15] proposed an efficient finite element model for static and dynamic analyses of FGP beams. They used an efficient three-nodded beam element which was based on a refined sinus model. The proposed beam element of these researchers does not require shear correction factor and ensures continuity conditions for displacements and transverse shear stresses as well as boundary conditions on the upper and lower surfaces of the FGP beam. Lee [22] used a layerwise finite element formulation to investigate the displacement and stress response of an FGP bimorph actuator. By using the refined 2D models, Brischetto and Carrera [23] studied the static response of a single layered FGP plate. In this work, Carrera's unified formulation has been extended to FGP plates in the framework of the principle of virtual displacements.

In 3D models, the governing differential equations of the 3D theory of piezoelasticity are solved using different analytical methods [7]. In these models, no a priori assumption for the displacement components and the electric potential along the thickness direction of FGP layers is introduced. To assess the validity of approximate theories related to FGP structures, obtaining analytical solutions based on the $3 \mathrm{D}$ theory of piezoelasticity is necessary [24]. By dividing the FGP layer into a number of homogeneous sub-layers, Reddy and Cheng [25] obtained a 3D solution for smart functionally gradient plates. Liu and Tani [26] used this sub-layer structure scheme to study the wave propagation in FGP plates. Chen and Ding [27] analyzed the free vibration of FGP rectangular plates using the aforementioned method. Based on the 3D theory of piezoelectricity, the method called state-space based DQM was employed by Li and Shi [28] to study the free vibration of an FGP beam under different boundary conditions. In this work, the FGP beam is also approximated as a multi layered cantilever. Zhong and Shang [29] presented an exact 3D solution for bending analysis of rectangular piezoelectric plates with exponent-law dependency of electromechanical properties on the thickness-coordinate by means of the state-space approach. Lu et al. [24] presented an exact solution for simply supported exponentially non-homogeneous piezoelectric laminates in cylindrical bending by Stroh-like formalism. Using this method, Lu et al. [30] also proposed the exact solutions for bending analysis of simply supported FGP plates. Liu and Shi [31] and Shi and Chen [32] obtained closed form solutions for the FGP cantilever beams using the $2 \mathrm{D}$ theory of piezoelasticity and the Airy stress function. Xiang and Shi [33] investigated thermoelectro-elastic response of an FGP sandwich cantilever. They also employed the Airy stress function in order to study the effect of parameters such as the electromechanical coupling, functionally graded index, temperature change, and thickness ratio on the static behavior of actuators/sensors. Lim and $\mathrm{He}$ [34] obtained an exact solution for a compositionally graded piezoelectric layer under uniform stretch, bending, and twisting. Lezgy-Nazargah [35] introduced a threedimensional exact state-space solution for cylindrical bending of continuously non-homogenous piezoelectric laminated plates with arbitrary gradient composition.

The exact 3D formulations available in the literature mostly consider the static bending of FGP structures. The rare exact $3 \mathrm{D}$ solutions can be found in the literature for the accurate dynamic analysis of 
FGP laminates. The available limited studies [25-28] which consider dynamic problems of FGP devices are based on this unjust assumption that the FGP layer consists of a number of homogeneous sub-layers. The preparation of input material data in these methods not only is very time consuming but also their solution accuracy depends strongly on the number of sub-layers. To fill in this gap in the literature, an exact 3D Peano series solution is derived in this study for the cylindrical bending vibration of FGP laminates based on the state-space approach. The obtained solution is exact in that the electric potential, displacements, and stresses exactly satisfy the governing motion equations of anisotropic piezoelasticity, the traction boundary conditions on the top and bottom planes, the end conditions, and the interlaminar continuity conditions on the interfaces between the layers. Unlike the sub-layer based methods [25-28], the present study considers FGP layers as the transversely nonhomogeneous piezoelectric material with continuous variation of electro-mechanical properties along the thickness direction. In deriving the present exact formulation, it is also assumed that all material properties are variable along the thickness direction of the laminates. In order to ensure that there is no algebraic errors in the implementation of the present state-space formulation, comparisons have been made with the results obtained from 2D finite element analysis (ABAQUS). The present obtained exact solution could serve as a basis for establishing simplified FGP beam/plate theories.

\section{Formulation of the problem}

The considered laminate is a prismatic one with a rectangular uniform cross section of length $L$, height $h$, and made of $N_{l}$ layers either completely or in part from FGP materials. The laminate is assumed to be infinitely long in the $x_{2}$-direction with perfect bonding between layers. The geometric parameters of the laminated plate and the chosen Cartesian coordinate system $\left(x_{2}, x_{2}, x_{3}\right)$ are shown in Figure 1.

The equations of motion in the absence of body

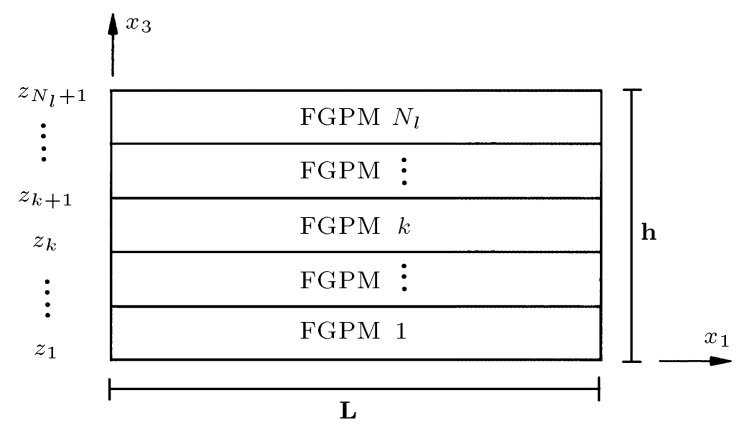

Figure 1. Functionally graded piezoelectric plate; Cartesian coordinate system and geometric parameters. forces and free charges for the $k$ th lamina made of a piezoelectric material are:

$$
\sigma_{i j, j}^{(k)}=\rho^{(k)} \ddot{u}_{i}^{(k)}, \quad D_{i, i}^{(k)}=0,
$$

where $\sigma_{i j}, u_{i}$, and $D_{i}$ denote the stress tensor, the displacement vector, and the electric displacement vector components, respectively. $\rho$ is the mass density, and a superimposed dot indicates differentiation with respect to time $t$.

In this study, the general type of piezoelectric materials is assumed to be "monoclinic class 2". The $3 \mathrm{D}$ linear constitutive equations of the $k$ th layer, polarized along its thickness direction in its global material coordinate system, can be expressed as:

$$
\left\{\begin{array}{l}
\boldsymbol{\sigma}^{(k)} \\
\mathbf{D}^{(k)}
\end{array}\right\}=\left[\begin{array}{cc}
\mathbf{c}^{(k)} & -\mathbf{e}^{(k)} \\
\mathbf{e}^{(e)} & \chi^{(k)}
\end{array}\right]\left\{\begin{array}{l}
\boldsymbol{\varepsilon}^{(k)} \\
\mathbf{E}^{(k)}
\end{array}\right\},
$$

where $\boldsymbol{\sigma}^{(k)}=\left\{\begin{array}{llllll}\sigma_{11}^{(k)} & \sigma_{22}^{(k)} & \sigma_{33}^{(k)} & \sigma_{23}^{(k)} & \sigma_{13}^{(k)} & \sigma_{12}^{(k)}\end{array}\right\}^{T}$ is the elastic stress vector, $\varepsilon^{(k)}=\left\{\begin{array}{lll}\varepsilon_{11}^{(k)} & \varepsilon_{22}^{(k)} & \varepsilon_{33}^{(k)}\end{array}\right.$

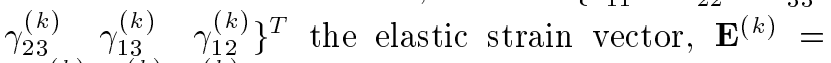
$\left\{E_{1}^{(k)} E_{2}^{(k)} E_{3}^{(k)}\right\}^{T}$ the electric field vector, and $\mathbf{D}^{(k)}=$ $\left\{D_{1}^{(k)} D_{2}^{(k)} D_{3}^{(k)}\right\}^{T}$ the electric displacement vector. The matrices $\mathbf{c}^{(k)}, \mathbf{e}^{(k)}$, and $\chi^{(k)}$ contain the elastic, piezoelectric, and dielectric coefficients, respectively. Unlike the homogeneous piezoelectric materials, $c_{m l}$, $e_{i m}$, and $\chi_{i j}$ are now functions of the coordinate $x_{3}$. They may vary according to the power law, exponent-law, or every other arbitrary distribution along the thickness direction of FGP layers. Indeed, the anisotropy of the considered laminated FGP medium of the present study belongs to the monoclinic class 2 with the symmetry axis 2 orthogonal to the layers.

The displacement components are related to the strain components through the relations:

$$
\varepsilon_{i j}^{(k)}=\frac{1}{2}\left(u_{i, j}^{(k)}+u_{j, i}^{(k)}\right) .
$$

The electric field components can be related to the electrostatic potential $\varphi$ using the relation:

$$
E_{i}^{(k)}=-\varphi_{, i}^{(k)}
$$

In cylindrical bending, the laminate is simply supported and the vertical edges are assumed to be grounded.

These conditions can be expressed as:

$$
\begin{aligned}
& \sigma_{11}^{(k)}\left(0, x_{3}\right)=\sigma_{11}^{(k)}\left(L, x_{3}\right)=0, \\
& \sigma_{12}^{(k)}\left(0, x_{3}\right)=\sigma_{12}^{(k)}\left(L, x_{3}\right)=0, \\
& u_{3}^{(k)}\left(0, x_{3}\right)=u_{3}^{(k)}\left(L, x_{3}\right)=0, \\
& \varphi^{(k)}\left(0, x_{3}\right)=\varphi^{(k)}\left(L, x_{3}\right)=0 .
\end{aligned}
$$


Although the electric potential does not vanish at the boundaries, exact 3D solutions for laminated plates can be obtained only for certain combinations of boundary conditions on the edges. In other words, we are able to obtain exact solutions only when the vertical edges of the laminated plate are assumed to be electrically grounded. Heyliger and Brooks [36] have also employed the same assumption in order to obtain the natural frequencies of laminated homogeneous piezoelectric plates in cylindrical bending. All Eqs. (1-6) must be satisfied for the material properties of a specific layer. In addition to these equations, the following mechanical and electrical boundary conditions on the upper and lower planes must be satisfied:

$$
\begin{aligned}
& \sigma_{33}\left(x_{1}, h\right)=q_{0}^{t} e^{i \omega t} \sin p x_{1}, \\
& \sigma_{33}\left(x_{1}, 0\right)=q_{0}^{b} e^{i \omega t} \sin p x_{1}, \\
& \sigma_{13}\left(x_{1}, h\right)=0, \quad \sigma_{13}\left(x_{1}, 0\right)=0, \\
& \sigma_{23}\left(x_{1}, h\right)=0, \quad \sigma_{23}\left(x_{1}, 0\right)=0, \\
& \varphi\left(x_{1}, h\right)=\varphi_{0}^{t} e^{i \omega t} \sin p x_{1} \text { or } D_{3}\left(x_{1}, h\right)=0, \\
& \varphi\left(x_{1}, 0\right)=\varphi_{0}^{b} e^{i \omega t} \sin p x_{1} \text { or } D_{3}\left(x_{1}, 0\right)=0,
\end{aligned}
$$

where $q_{0}^{t}, q_{0}^{b}, \varphi_{0}^{t}$, and $\varphi_{0}^{b}$ are known constants; $p=$ $n \pi / L$, and $n$ is a positive integer; $i=\sqrt{-1}$; and $\omega$ and $t$ denote the angular frequency and time, respectively. It is worth to note that any arbitrary applied traction load or prescribed electric potential on the surfaces of the FGP laminates can be expanded in terms of a sinusoidal (Fourier) series. Also, the following interlaminar continuity conditions on the interfaces between the layers must be ensured:

$$
\begin{aligned}
& \sigma_{3 i}^{(k)}\left(x_{1}, z_{k+1}\right)=\sigma_{3 i}^{(k+1)}\left(x_{1}, z_{k+1}\right), \\
& u_{i}^{(k)}\left(x_{1}, z_{k+1}\right)=u_{i}^{(k+1)}\left(x_{1}, z_{k+1}\right), \\
& \varphi^{(k)}\left(x_{1}, z_{k+1}\right)=\varphi^{(k)}\left(x_{1}, z_{k+1}\right), \\
& D_{3}^{(k)}\left(x_{1}, z_{k+1}\right)=D_{3}^{(k+1)}\left(x_{1}, z_{k+1}\right) .
\end{aligned}
$$

\section{Exact solution}

A solution in the following form is sought for the displacement components and the electric potential of the $k$ th lamina:

$$
\begin{aligned}
& u_{1}^{(k)}\left(x_{1}, x_{3}, t\right)=U^{(k)}\left(x_{3}\right) e^{i \omega t} \cos p x_{1}, \\
& u_{2}^{(k)}\left(x_{1}, x_{3}, t\right)=V^{(k)}\left(x_{3}\right) e^{i \omega t} \cos p x_{1}, \\
& u_{3}^{(k)}\left(x_{1}, x_{3}, t\right)=W^{(k)}\left(x_{3}\right) e^{i \omega t} \sin p x_{1}, \\
& \varphi^{(k)}\left(x_{1}, x_{3}, t\right)=\Phi^{(k)}\left(x_{3}\right) e^{i \omega t} \sin p x_{1} .
\end{aligned}
$$

The above assumed solution is reasonable because the laminates are of infinite extent in the $x_{2}$-direction and the applied loads and material properties are independent of $x_{2}$. Indeed, the laminates are in a generalized plane state of deformation. Moreover, it can be observed that Eq. (9) identically satisfy the boundary conditions (5)-(6) on the edges $x_{1}=0$ and $x_{1}=L$. It is worth to note that no assumption for $U^{(k)}\left(x_{3}\right), \quad V^{(k)}\left(x_{3}\right), \quad W^{(k)}\left(x_{3}\right)$, and $\Phi^{(k)}\left(x_{3}\right)$ is introduced in Eq. (9). They are unknown functions that must be determined. Substitution of Eq. (9) into Eqs. (3)-(4) and the result into Eq. (2) gives the stresses and electric displacements with respect to the independent unknown field variables $U^{(k)}\left(x_{3}\right)$, $V^{(k)}\left(x_{3}\right), W^{(k)}\left(x_{3}\right)$, and $\Phi^{(k)}\left(x_{3}\right)$. By substitution of these rewritten stress and electric displacement components into the governing equilibrium equation (Eq. (1)), and expressing the resulting system of second-order differential equations as a set of first-order differential equations, the following state-space matrix equation can be obtained:

$$
\mathbf{K}^{(k)} \mathbf{X}_{, 3}^{(k)}+\mathbf{B}^{(k)} \mathbf{X}^{(k)}=0
$$

or:

$$
\mathbf{X}_{, 3}^{(k)}=\mathbf{A}^{(k)} \mathbf{X}^{(k)},
$$

where $A^{(k)}, K^{(k)}, B^{(k)}$ and $X^{(k)}$ are calculated by the equations shown in Box I.

For the homogeneous piezoelectric layers, the matrix $\mathbf{A}^{(k)}$ in basic Eq. (11) decreases to a constant matrix. In this case, the solution of Eq. (11) can be written as [37-38]:

$$
\mathbf{X}^{(k)}=\exp \left[\mathbf{A}^{(k)} x_{3}\right] \boldsymbol{\delta}^{(k)}
$$

where $\boldsymbol{\delta}^{(k)}$ is an $8 \times 1$ vector of unknown constants. For the FGP layers with arbitrary compositional gradient, it is obvious that the components of matrix $\mathbf{A}^{(k)}$ in Eq. (11) are not constant. It is evident that they are now functions of the coordinate $x_{3}$. Thus, the typical solution $\mathbf{X}^{(k)}=\exp \left[\mathbf{A}^{(k)} x_{3}\right] \boldsymbol{\delta}^{(k)}$ is no longer valid for Eq. (11). In mathematics and mechanics of inhomogeneous media, the solution to Eq. (11) can be written as [37-39]:

$$
\mathbf{X}^{(k)}=\mathbf{W}^{(k)}\left(x_{3}\right) \boldsymbol{\delta}^{(k)}
$$

where $\mathbf{W}^{(k)}\left(x_{3}\right)=\operatorname{Ord} \exp \left[\int_{0}^{x_{3}} \mathbf{A}^{(k)}(x) d x\right]$ is called the propagator matrix, which can be expressed as the following Peano expansion [37-38]:

$$
\mathbf{W}^{(k)}\left(x_{3}\right)=\mathbf{I}+\int_{0}^{x_{3}} \mathbf{A}^{(k)}(x) d x+\int_{0}^{x_{3}} \mathbf{A}^{(k)}(x)
$$




$$
\mathbf{K}^{(k)}=\left[\begin{array}{cccccccc}
1 & 0 & 0 & 0 & 0 & 0 & 0 & 0 \\
0 & 1 & 0 & 0 & 0 & 0 & 0 & 0 \\
0 & 0 & 1 & 0 & 0 & 0 & 0 & 0 \\
0 & 0 & 0 & 1 & 0 & 0 & 0 & 0 \\
0 & 0 & 0 & 0 & c_{55}\left(x_{3}\right) & c_{45}\left(x_{3}\right) & 0 & 0 \\
0 & 0 & 0 & 0 & c_{45}\left(x_{3}\right) & c_{44}\left(x_{3}\right) & 0 & 0 \\
0 & 0 & 0 & 0 & 0 & 0 & c_{33}\left(x_{3}\right) & e_{33}\left(x_{3}\right) \\
0 & 0 & 0 & 0 & 0 & 0 & e_{33}\left(x_{3}\right) & -\chi_{33}\left(x_{3}\right)
\end{array}\right]
$$

$\mathbf{A}^{(k)}=-\left(\mathbf{K}^{(k)}\right)^{-1} \mathbf{B}^{(k)}$

$$
\mathbf{X}^{(k)}=\left[U^{(k)}\left(x_{3}\right) V^{(k)}\left(x_{3}\right) W^{(k)}\left(x_{3}\right) \Phi^{(k)}\left(x_{3}\right)\right.
$$

$$
\left.\frac{d U^{(k)}\left(x_{3}\right)}{d x_{3}} \frac{d V^{(k)}\left(x_{3}\right)}{d x_{3}} \frac{d W^{(k)}\left(x_{3}\right)}{d x_{3}} \frac{d \Phi^{(k)}\left(x_{3}\right)}{d x_{3}}\right]^{T}
$$

$$
\mathbf{B}^{(k)}=\left[\begin{array}{cccc}
0 & 0 & 0 & 0 \\
0 & 0 & 0 & 0 \\
0 & 0 & 0 & 0 \\
0 & 0 & 0 & 0 \\
-p^{2} c_{11}\left(x_{3}\right)+\rho \omega^{2} & -p^{2} c_{16}\left(x_{3}\right) & p \frac{d c_{55}\left(x_{3}\right)}{d x_{3}} & p \frac{d e_{15}\left(x_{3}\right)}{d x_{3}} \\
-p^{2} c_{16}\left(x_{3}\right) & -p^{2} c_{66}\left(x_{3}\right)+\rho \omega^{2} & p \frac{d c_{45}\left(x_{3}\right)}{d x_{3}} & p \frac{d e_{14}\left(x_{3}\right)}{d x_{3}} \\
-p \frac{d c_{13}\left(x_{3}\right)}{d x_{3}} & -p \frac{d c_{36}\left(x_{3}\right)}{d x_{3}} & -p^{2} c_{55}\left(x_{3}\right)+\rho \omega^{2} & -p^{2} e_{15}\left(x_{3}\right) \\
-p \frac{d e_{31}\left(x_{3}\right)}{d x_{3}} & -p \frac{d e_{36}\left(x_{3}\right)}{d x_{3}} & -p^{2} e_{15}\left(x_{3}\right) & p^{2} \chi_{11}\left(x_{3}\right)
\end{array}\right.
$$

$$
\left.\begin{array}{cccc}
-1 & 0 & 0 & 0 \\
0 & -1 & 0 & 0 \\
0 & 0 & -1 & 0 \\
0 & 0 & 0 & -1 \\
\frac{d c_{55}\left(x_{3}\right)}{d x_{3}} & \frac{d c_{45}\left(x_{3}\right)}{d x_{3}} & p\left(c_{13}\left(x_{3}\right)+c_{55}\left(x_{3}\right)\right) & p\left(e_{31}\left(x_{3}\right)+e_{15}\left(x_{3}\right)\right) \\
\frac{d c_{45}\left(x_{3}\right)}{d x_{3}} & \frac{d c_{44}\left(x_{3}\right)}{d x_{3}} & p\left(c_{36}\left(x_{3}\right)+c_{45}\left(x_{3}\right)\right) & p\left(e_{36}\left(x_{3}\right)+e_{14}\left(x_{3}\right)\right) \\
\left.\left.x_{3}\right)+c_{13}\left(x_{3}\right)\right) & -p\left(c_{45}\left(x_{3}\right)+c_{36}\left(x_{3}\right)\right) & \frac{d c_{33}\left(c_{3}\right)}{d x_{3}} & \frac{d e_{33}\left(x_{3}\right)}{d x_{3}} \\
\left.\left.x_{3}\right)+e_{31}\left(x_{3}\right)\right) & -p\left(e_{14}\left(x_{3}\right)+e_{36}\left(x_{3}\right)\right) & \frac{d e_{33}\left(x_{3}\right)}{d x_{3}} & -\frac{d \chi_{33}\left(x_{3}\right)}{d x_{3}}
\end{array}\right],
$$

Box I

$$
\begin{aligned}
& \int_{0}^{x} \mathbf{A}^{(k)}\left(y_{1}\right) d y_{1} d x+\int_{0}^{x_{3}} \mathbf{A}^{(k)}(x) \\
& \int_{0}^{x} \mathbf{A}^{(k)}\left(y_{1}\right) \int_{0}^{y_{1}} \mathbf{A}^{(k)}\left(y_{2}\right) d y_{2} d y_{1} d x+\ldots
\end{aligned}
$$

Thus, the solutions for the displacement components, $u_{i}$, and the electric potential, $\varphi$, are expressed in terms of eight unknown constants for each of the $N_{l}$ layers. This yields $8 N_{l}$ total unknowns for the complete FGP laminates. These constants are determined by satisfying the boundary and interface continuity conditions at the upper and lower surfaces of each layer. There are four boundary conditions at the top of layer $N_{l}$ and the bottom of layer 1 with a total of eight boundary conditions (Eq. (7)). At each interface, the continuity conditions as expressed in Eq. (8) must be ensured, leading to $8\left(N_{l}-1\right)$ equations. Thus, the total number of equations and unknowns is $8 N_{l}$. These equations can be expressed in the following matrix form:

$$
\mathbf{K} \delta=\mathbf{f}
$$

\subsection{Forced vibration analysis}

In case of forced vibration analysis, the focus is on the steady-state response of the FGP laminates due to harmonic distributed normal loads or electric potential on the top and/or bottom planes. In this case, $n$ and $\omega$ are known from the prescribed harmonic loads as stated in Eq. (7). Thus, the matrix $\mathbf{K}$ and the vector 
f in Eq. (16) are known matrices whose elements can be calculated according the procedure explained above. This linear system of equations can be solved in order to obtain $8 N_{l}$ constants of layers (elements of vector $\boldsymbol{\delta}$ ). Once these constants are determined, the mechanical displacements, stresses, electric potential, and electric displacements can be evaluated at any location within the FGP laminates.

\subsection{Free vibration analysis}

In case of free vibration, the FGP laminates are not subject to any applied mechanical or electrical loads. Thus, $\mathbf{K}$ is an $8 N_{l} \times 8 N_{l}$ matrix whose elements are dependent on the unknown natural frequencies $\omega$. The satisfaction of the interlaminar continuity conditions on the interfaces between the layers, and the homogeneous boundary conditions on the upper and lower surfaces of the FGP laminates results in the following homogeneous matrix equation:

$$
\mathbf{K}(\omega) \delta=\mathbf{0}
$$

A non-trivial solution for $\delta$ can be obtained by setting the determinant $|\mathbf{K}(\omega)|$ equal to zero. Solving the resulting polynomial equation yields the values of the natural frequencies (eigenvalues) $\omega$. For every $n$, there are an infinite number of values for $\omega$ that satisfy Eq. (17). They can be arranged in ascending order as $\left\{\omega_{n}^{(1)}, \omega_{n}^{(2)}, \omega_{n}^{(3)}, \ldots\right\} \cdot \omega_{n}^{(1)}$ denotes the natural frequency corresponding to the $n$th bending mode of the FGP laminates while $\omega_{n}^{(2)}, \omega_{n}^{(3)}, \ldots$ are the natural frequencies corresponding to the thickness modes of the FGP laminates. The eigenvector $\boldsymbol{\delta}^{(j)}$ corresponding to the natural frequency $\omega_{n}^{(j)}$ may be determined from the null-space of $\mathbf{K}\left(\omega_{n}^{(j)}\right)$. The displacements, electric potential, stresses, and electric displacement at any point within the FGP laminates can be determined using the $8 N_{l}$ constants obtained from the eigenvector $\boldsymbol{\delta}^{(j)}$.

\section{Numerical results and discussion}

Free and forced vibration analyses of some FGP laminates have been considered in this section. The results of the present formulation are compared with the results obtained from $2 \mathrm{D}$ finite element analysis (ABAQUS) to ensure that there is no algebraic error in the implementation of the present exact solution. It is worth to note that all the matrix manipulations in this paper have been done using a program code written in MATLAB software. The latter was also employed to numerically find the values for the frequencies that ensure the characteristic Eq. (17). To this aim, the frequency was stepped through a sequence of small increments and the sign of the determinant was computed. Evaluating this parameter as a function of frequency yields regions near a zero determinant.
The values for $\omega$ that yielded a zero determinant were estimated to the required accuracy using the bisection method. Although the first example of the present section is mainly devoted to the verification purposes, the other examples included in the following sections contain new results.

\subsection{Example 1}

In order to have a comparison with other investigations, the cylindrical bending vibration of a two-layer piezoelectric laminate is considered in this section. The laminate is composed of two dissimilar piezoelectric materials A and B. Both layers of the laminate have equal thicknesses and the total thickness is $h=0.01 \mathrm{~m}$. For the length-to-thickness ratio, two values $S(L / h)=$ 4 and $S=50$ are considered. The present two-layer piezoelectric laminate has also been studied by Heyliger and Brooks [36]. The resulting natural frequencies $\left(\omega_{n}^{(j)}\right)$ are shown in Table 1 for both Open Circuit (OC) and Closed Circuit (CC) electric boundary conditions. The results are given in terms of natural frequencies in radian per seconds. In this table, the present results have been compared with those obtained by Heyliger and Brooks [36]. It can be observed that the present results are in excellent agreement with exact solutions of Heyliger and Brooks [36].

\subsection{Example 2}

In this example, free vibration of a single layer FGP strip with the thickness $h=0.001 \mathrm{~m}$ and length-tothickness ratio $S=5$ (thick strip) is considered. The considered strip is made of a PZT-4 based exponentially graded piezoelectric material with the following material properties:

$$
\begin{aligned}
& c_{m l}=c_{m l}^{0} f\left(x_{3}\right), \quad e_{i m}=e_{i m}^{0} f\left(x_{3}\right), \\
& \chi_{i j}=\chi_{i j}^{0} f\left(x_{3}\right), \quad \rho=\rho^{0} f\left(x_{3}\right),
\end{aligned}
$$

where:

$$
f\left(x_{3}\right)=e^{a x_{3} / h}, \quad 0<x_{3}<0.001
$$

and $a$ is a constant characterizing the degree of the material gradient along $x_{3} \cdot c_{m l}^{0}, e_{i m}^{0}, \chi_{i j}^{0}$, and $\rho^{0}$ are the values of material properties at the plane $x_{3}=0$. The mechanical and electrical properties of the employed PZT-4 are the same as those cited in [13]. The strip is simply supported along two edges. The bottom plane of the FGP strip is assumed to be grounded (zero potential).

The natural frequencies $\left(\omega_{n}^{(j)}\right)$ of thick FGP strip with OC electric boundary conditions have been calculated for $n=1,2,3, \ldots$ The lowest 12 natural frequencies are shown in Table 2 for three different material gradient indexes 1,0 , and -1 . Homogeneous piezoelectric material is recovered for $a=0$. It 
Table 1. Natural frequencies of the two-layer piezoelectric laminated plate.

\begin{tabular}{|c|c|c|c|c|c|}
\hline \multirow{3}{*}{$S$} & \multirow{3}{*}{ Mode } & \multicolumn{4}{|c|}{$\omega / 100$} \\
\hline & & \multicolumn{2}{|c|}{ Closed circuit } & \multicolumn{2}{|c|}{ Open circuit } \\
\hline & & $\begin{array}{c}\text { Heyliger and } \\
\text { Brooks [36] }\end{array}$ & Present & $\begin{array}{c}\text { Heyliger and } \\
\text { Brooks [36] }\end{array}$ & Present \\
\hline \multirow[t]{10}{*}{$S=4$} & $\omega_{1}^{(1)}$ & 56492.87 & 56492.85 & 57056.04 & 57056.01 \\
\hline & $\omega_{1}^{(2)}$ & 272572.3 & 272571.9 & 275664.7 & 275664.3 \\
\hline & $\omega_{1}^{(3)}$ & 642549.6 & 642548.5 & 717847.4 & 717846.9 \\
\hline & $\omega_{1}^{(4)}$ & 1078116 & 1078109 & 1129993 & 1129987 \\
\hline & $\omega_{1}^{(5)}$ & 1302643 & 1302631 & 1371236 & 1371230 \\
\hline & $\omega_{1}^{(6)}$ & 1765606 & 1765599 & 1773905 & 1773896 \\
\hline & $\omega_{1}^{(7)}$ & 2383141 & 2383128 & 2414676 & 2414669 \\
\hline & $\omega_{1}^{(8)}$ & 2426698 & 2426683 & 2457413 & 2457406 \\
\hline & $\omega_{1}^{(9)}$ & 2992976 & 2992967 & 3023384 & 3023375 \\
\hline & $\omega_{1}^{(10)}$ & 3556566 & 3556553 & 3562834 & 3562826 \\
\hline \multirow[t]{10}{*}{$S=50$} & $\omega_{1}^{(1)}$ & 398.0712 & 398.0709 & 399.5398 & 399.5387 \\
\hline & $\omega_{1}^{(2)}$ & 22037.71 & 22037.69 & 22199.65 & 22199.59 \\
\hline & $\omega_{1}^{(3)}$ & 578761.6 & 578761.0 & 656277.1 & 656276.6 \\
\hline & $\omega_{1}^{(4)}$ & 1119205 & 1119198 & 1209600 & 1209593 \\
\hline & $\omega_{1}^{(5)}$ & 1230936 & 1230927 & 1231074 & 1231066 \\
\hline & $\omega_{1}^{(6)}$ & 1758431 & 1758428 & 1766933 & 1766923 \\
\hline & $\omega_{1}^{(7)}$ & 2377974 & 2377969 & 2419966 & 2419954 \\
\hline & $\omega_{1}^{(8)}$ & 2416459 & 2416451 & 2435533 & 2435525 \\
\hline & $\omega_{1}^{(9)}$ & 2984263 & 2984256 & 3012504 & 3012692 \\
\hline & $\omega_{1}^{(10)}$ & 3573218 & 3573208 & 3577041 & 3577031 \\
\hline
\end{tabular}

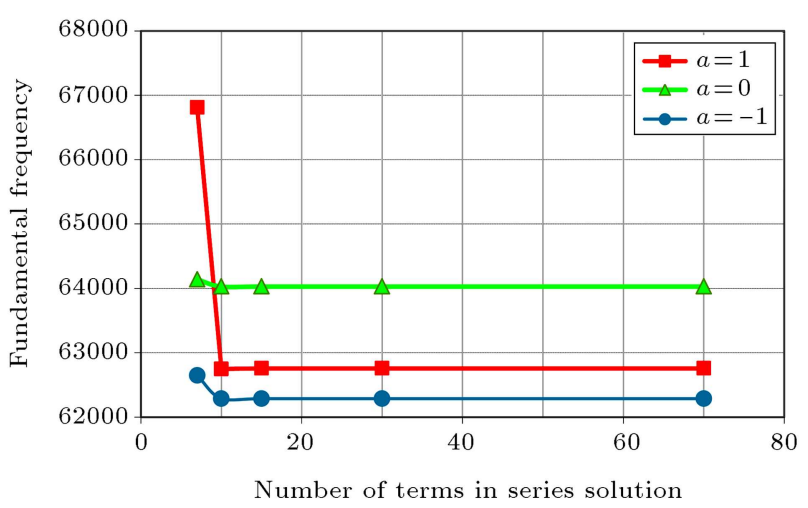

Figure 2. The lowest frequency versus the number of terms in series solution.

gives a better insight about the effect of continuous through-the-thickness variations of material properties on the natural frequencies of piezoelectric laminates. In Table 2, the mode shapes are defined as Bend and Th for bending and thickness modes, respectively. Figure 2 shows the changes of the lowest frequency of the thick FGP strip with respect to the number of employed terms in calculation of the propagator matrix (Eq. (15)). It is seen from Figure 2 that

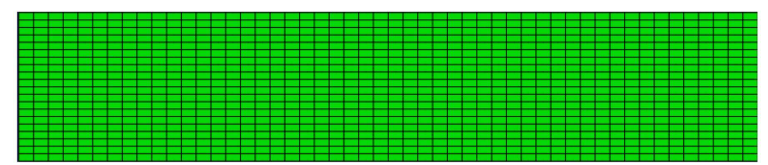

Figure 3. Functionally graded piezoelectric plate; mesh with 1000 elements (ABAQUS).

the proposed Peano series solution has a fast speed of convergence. Twenty terms in the series solution (Eq. (15)) are enough to get satisfactory accuracy for the lowest frequency. The same study is performed using ABAQUS with 8-node bi-quadratic plane strain elements. To this end, the thickness of the FGP strip was discretized into several thin homogeneous layers with different electrical and mechanical material properties. The mesh with 1000 elements (9423 dofs) as showed in Figure 3 yields converged results. For solving the eigenvalue problem, the Lanczos method available in the software was employed. In Table 2, the results of ABAQUS software have also been shown and compared with the present results. It is observed that the natural frequencies predicted by the proposed exact solution are in very good agreement with the ABAQUS results. For different values of material gradient index, 
Table 2. Open circuit natural frequencies of the single-layer FGP strip $(S=5)$.

\begin{tabular}{|c|c|c|c|c|}
\hline \multirow{2}{*}{$\begin{array}{c}\text { Material } \\
\text { gradient } \\
\text { index }\end{array}$} & \multicolumn{4}{|c|}{ Natural frequencies $(\mathrm{Hz})$} \\
\hline & Mode & Present & ABAQUS & $\begin{array}{c}\text { Difference } \\
(\%)\end{array}$ \\
\hline \multirow[t]{12}{*}{$a=1$} & $\omega_{1}^{(1)}$ (Bend) & 62758 & 62757 & 0.00 \\
\hline & $\omega_{2}^{(1)}$ (Bend) & 216733 & 216722 & 0.01 \\
\hline & $\omega_{1}^{(2)}(\mathrm{Th})$ & 371672 & 371674 & 0.00 \\
\hline & $\omega_{3}^{(1)}$ (Bend) & 413050 & 413018 & 0.01 \\
\hline & $\omega_{4}^{(1)}($ Bend $)$ & 625720 & 625661 & 0.01 \\
\hline & $\omega_{2}^{(2)}(\mathrm{Th})$ & 714830 & 714831 & 0.00 \\
\hline & $\omega_{5}^{(1)}$ (Bend) & 843644 & 843560 & 0.01 \\
\hline & $\omega_{3}^{(2)}(\mathrm{Th})$ & 1013799 & 1013780 & 0.00 \\
\hline & $\omega_{1}^{(3)}(\mathrm{Th})$ & 1019253 & 1019140 & 0.01 \\
\hline & $\omega_{6}^{(1)}($ Bend $)$ & 1062100 & 1062000 & 0.01 \\
\hline & $\omega_{2}^{(3)}(\mathrm{Th})$ & 1210273 & 1210160 & 0.01 \\
\hline & $\omega_{4}^{(2)}(\mathrm{Th})$ & 1243814 & 1243750 & 0.01 \\
\hline \multirow[t]{12}{*}{$a=0$} & $\omega_{1}^{(1)}(\mathrm{Bend})$ & 64028 & 64028 & 0 \\
\hline & $\omega_{2}^{(1)}($ Bend $)$ & 220065 & 220063 & 0.00 \\
\hline & $\omega_{1}^{(2)}(\mathrm{Th})$ & 372330 & 372330 & 0 \\
\hline & $\omega_{3}^{(1)}($ Bend $)$ & 419038 & 419039 & 0.00 \\
\hline & $\omega_{4}^{(1)}(\mathrm{Bend})$ & 635329 & 635332 & 0.00 \\
\hline & $\omega_{2}^{(2)}(\mathrm{Th})$ & 714699 & 714699 & 0 \\
\hline & $\omega_{5}^{(1)}($ Bend $)$ & 857713 & 857722 & 0.00 \\
\hline & $\omega_{3}^{(2)}(\mathrm{Th})$ & 1007303 & 1007300 & 0.00 \\
\hline & $\omega_{1}^{(3)}(\mathrm{Th})$ & 1007831 & 1007830 & 0.00 \\
\hline & $\omega_{6}^{(1)}($ Bend $)$ & 1081314 & 1081340 & 0.00 \\
\hline & $\omega_{2}^{(3)}(\mathrm{Th})$ & 1204103 & 1204100 & 0.00 \\
\hline & $\omega_{4}^{(2)}(\mathrm{Th})$ & 1226441 & 1226440 & 0.00 \\
\hline \multirow[t]{12}{*}{$a=-1$} & $\omega_{1}^{(1)}(\mathrm{Bend})$ & 62287 & 61752 & 0.87 \\
\hline & $\omega_{2}^{(1)}($ Bend $)$ & 213170 & 211904 & 0.60 \\
\hline & $\omega_{1}^{(2)}(\mathrm{Th})$ & 373381 & 371123 & 0.61 \\
\hline & $\omega_{3}^{(1)}($ Bend $)$ & 405167 & 403447 & 0.43 \\
\hline & $\omega_{4}^{(1)}($ Bend $)$ & 614010 & 611996 & 0.33 \\
\hline & $\omega_{2}^{(2)}(\mathrm{Th})$ & 719613 & 714130 & 0.77 \\
\hline & $\omega_{5}^{(1)}$ (Bend) & 828620 & 826375 & 0.27 \\
\hline & $\omega_{3}^{(2)}(\mathrm{Th})$ & 1019283 & 1011130 & 0.81 \\
\hline & $\omega_{1}^{(3)}(\mathrm{Th})$ & 1019456 & 1017660 & 0.18 \\
\hline & $\omega_{6}^{(1)}($ Bend $)$ & 1043843 & 1041390 & 0.24 \\
\hline & $\omega_{2}^{(3)}(\mathrm{Th})$ & 1219363 & 1214640 & 0.39 \\
\hline & $\omega_{4}^{(2)}(\mathrm{Th})$ & 1251246 & 1244150 & 0.57 \\
\hline
\end{tabular}

the maximum discrepancy between the present results and those obtained from $2 \mathrm{D}$ finite element results is about $1 \%$. The analytically obtained first 12 mode shapes for $S=5$ and electrically open circuit boundary conditions are shown in Figure 4. Although the strip

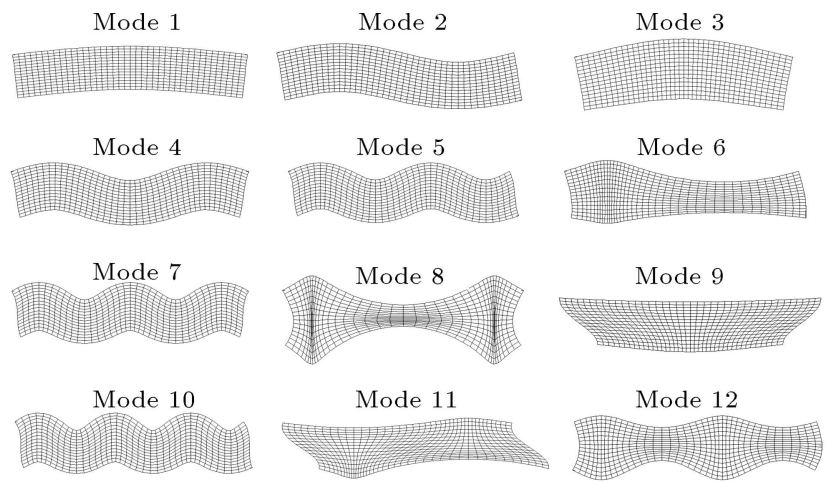

Figure 4. The first twelve mode shapes of the simply supported FGP plate with $a=1$; OC electric boundary conditions $(S=5)$.

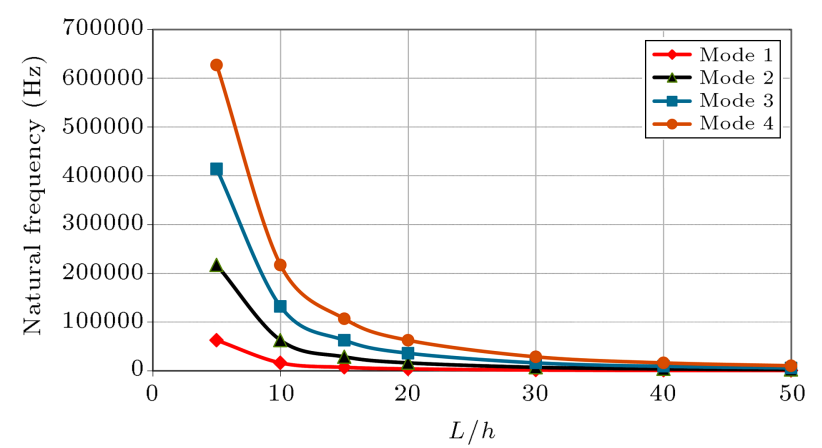

Figure 5. Effect of $L / h$ on the first four fundamental frequencies of FGP plates with $a=1$.

is assumed to be of infinite width in the $x_{2}$-direction, the mode shapes are depicted in the $2 \mathrm{D}$ space for the purpose of illustration. It can also be observed from Table 2 that with increase in the absolute values of material gradient index $a$, the natural frequencies of the FGP strip decrease. The intensity of this phenomenon is more dominant in case of negative values of $a$.

Figure 5 addresses the effect of the aspect ratio $S$ on the first four natural fundamental frequencies of FGP strips. The material gradient index is $a=1$ and the electric boundary condition is assumed to be OC. A sharp decrease in the natural frequency occurs for the thick FGP strips. This effect is particularly dominant for the fourth fundamental natural frequency. For $S>40$, the sensitivity to the aspect ratio decreases regardless of the modes of vibration.

\subsection{Example 3}

The free vibration of a two-layer FGP laminate with the thickness $h=0.001 \mathrm{~m}$ and length-to-thickness ratio $S=5$ is considered in this section. The lower layer is made of a homogeneous PZT-4 piezoelectric material. The upper layer is a PZT-4 based exponentially graded piezoelectric layer with the following material properties:

$$
c_{m l}=c_{m l}^{0} f\left(x_{3}\right), \quad e_{i m}=e_{i m}^{0} f\left(x_{3}\right),
$$


Table 3. Open circuit natural frequencies of the two-layer FGP laminate $(S=5)$.

\begin{tabular}{|c|c|c|c|c|}
\hline \multirow{2}{*}{$\begin{array}{l}\text { Material } \\
\text { gradient } \\
\text { index }\end{array}$} & \multicolumn{4}{|c|}{ Natural frequencies $(\mathrm{Hz})$} \\
\hline & Mode & Present & ABAQUS & $\begin{array}{c}\text { Difference } \\
(\%)\end{array}$ \\
\hline \multirow[t]{12}{*}{$a=1$} & $\omega_{1}^{(1)}$ (Bend) & 63533 & 63523 & 0.02 \\
\hline & $\omega_{2}^{(1)}$ (Bend) & 218457 & 218426 & 0.01 \\
\hline & $\omega_{1}^{(2)}(\mathrm{Th})$ & 371629 & 371632 & 0.00 \\
\hline & $\omega_{3}^{(1)}($ Bend $)$ & 414998 & 414942 & 0.01 \\
\hline & $\omega_{4}^{(1)}($ Bend $)$ & 627333 & 627255 & 0.01 \\
\hline & $\omega_{2}^{(2)}(\mathrm{Th})$ & 713768 & 713780 & 0.00 \\
\hline & $\omega_{5}^{(1)}(\mathrm{Bend})$ & 844648 & 844552 & 0.01 \\
\hline & $\omega_{1}^{(3)}(\mathrm{Th})$ & 1008885 & 1008910 & 0.00 \\
\hline & $\omega_{3}^{(2)}(\mathrm{Th})$ & 1001648 & 1001680 & 0.00 \\
\hline & $\omega_{6}^{(1)}(\mathrm{Bend})$ & 1062433 & 1062330 & 0.01 \\
\hline & $\omega_{2}^{(3)}(\mathrm{Th})$ & 1193562 & 1193590 & 0.00 \\
\hline & $\omega_{4}^{(2)}(\mathrm{Th})$ & 1231372 & 1231410 & 0.00 \\
\hline \multirow[t]{12}{*}{$a=-1$} & $\omega_{1}^{(1)}($ Bend $)$ & 61894 & 61812 & 0.13 \\
\hline & $\omega_{2}^{(1)}($ Bend $)$ & 212853 & 212788 & 0.03 \\
\hline & $\omega_{1}^{(2)}(\mathrm{Th})$ & 373323 & 371300 & 0.54 \\
\hline & $\omega_{3}^{(1)}($ Bend $)$ & 406136 & 406171 & 0.01 \\
\hline & $\omega_{4}^{(1)}($ Bend $)$ & 617253 & 617245 & 0.00 \\
\hline & $\omega_{2}^{(2)}(\mathrm{Th})$ & 719610 & 713674 & 0.83 \\
\hline & $\omega_{5}^{(1)}(\mathrm{Bend})$ & 834935 & 834535 & 0.05 \\
\hline & $\omega_{3}^{(2)}(\mathrm{Th})$ & 1020619 & 1008030 & 1.25 \\
\hline & $\omega_{1}^{(3)}(\mathrm{Th})$ & 1033281 & 1031640 & 0.16 \\
\hline & $\omega_{6}^{(1)}($ Bend $)$ & 1053974 & 1052620 & 0.13 \\
\hline & $\omega_{2}^{(3)}(\mathrm{Th})$ & 1231906 & 1227590 & 0.35 \\
\hline & $\omega_{4}^{(2)}(\mathrm{Th})$ & 1236021 & 1236570 & 0.04 \\
\hline
\end{tabular}

$$
\chi_{i j}=\chi_{i j}^{0} f\left(x_{3}\right), \quad \rho=\rho^{0} f\left(x_{3}\right),
$$

where:

$$
f\left(x_{3}\right)=e^{a\left(x_{3}-0.0002\right) / h}, \quad 0.0002<x_{3}<0.001 .
$$

The ratio of the upper graded layer to the lower homogeneous layer has been taken as 4 . It is pointed out that $c_{m l}^{0}, e_{i m}^{0}, \chi_{i j}^{0}$, and $\rho^{0}$ in the present example are the values of material properties at the bottom of the top layer. Concerning the material property gradient index $a$, two values $a=-1$ and $a=1$ are chosen. The first 12 natural frequencies of the thick two-layer FGP laminate are shown in Table 3 for different values of aspect ratio. The assumed electric boundary condition is OC. Similar to the previous example, the obtained numerical results have been compared with the results obtained from 2D finite element analysis. Again, the agreement between the present and ABAQUS results is very good. The maximum percent of discrepancy
Table 4. Closed circuit natural frequencies of the

\begin{tabular}{|c|c|c|c|c|}
\hline \multirow{2}{*}{$\begin{array}{c}\text { Material } \\
\text { gradient } \\
\text { index }\end{array}$} & \multicolumn{4}{|c|}{ Natural frequencies $(\mathrm{Hz})$} \\
\hline & Mode & Present & ABAQUS & $\begin{array}{c}\text { Difference } \\
(\%)\end{array}$ \\
\hline \multirow[t]{12}{*}{$a=1$} & $\omega_{1}^{(1)}$ (Bend) & 62931 & 62924 & 0.01 \\
\hline & $\omega_{2}^{(1)}$ (Bend) & 215069 & 215050 & 0.01 \\
\hline & $\omega_{1}^{(2)}(\mathrm{Th})$ & 347985 & 347981 & 0.00 \\
\hline & $\omega_{3}^{(1)}($ Bend $)$ & 407260 & 407231 & 0.01 \\
\hline & $\omega_{4}^{(1)}$ (Bend) & 615244 & 615212 & 0.01 \\
\hline & $\omega_{2}^{(2)}(\mathrm{Th})$ & 680080 & 680079 & 0.00 \\
\hline & $\omega_{5}^{(1)}($ Bend $)$ & 828704 & 828679 & 0.00 \\
\hline & $\omega_{3}^{(2)}(\mathrm{Th})$ & 973543 & 973557 & 0.00 \\
\hline & $\omega_{1}^{(3)}(\mathrm{Th})$ & 987965 & 988002 & 0.00 \\
\hline & $\omega_{6}^{(1)}($ Bend $)$ & 1042972 & 1042970 & 0.00 \\
\hline & $\omega_{2}^{(3)}(\mathrm{Th})$ & 1159873 & 1159910 & 0.00 \\
\hline & $\omega_{4}^{(2)}(\mathrm{Th})$ & 1201829 & 1201860 & 0.00 \\
\hline \multirow[t]{12}{*}{$a=-1$} & $\omega_{1}^{(1)}$ (Bend) & 61746 & 61683 & 0.10 \\
\hline & $\omega_{2}^{(1)}($ Bend $)$ & 212846 & 212785 & 0.03 \\
\hline & $\omega_{1}^{(2)}(\mathrm{Th})$ & 348150 & 345341 & 0.81 \\
\hline & $\omega_{3}^{(1)}$ (Bend) & 405919 & 405945 & 0.01 \\
\hline & $\omega_{4}^{(1)}($ Bend $)$ & 616408 & 616407 & 0.00 \\
\hline & $\omega_{2}^{(2)}(\mathrm{Th})$ & 681632 & 675111 & 0.97 \\
\hline & $\omega_{5}^{(1)}($ Bend $)$ & 833480 & 833114 & 0.04 \\
\hline & $\omega_{3}^{(2)}(\mathrm{Th})$ & 979999 & 968180 & 1.22 \\
\hline & $\omega_{1}^{(3)}(\mathrm{Th})$ & 1018076 & 1016880 & 0.12 \\
\hline & $\omega_{6}^{(1)}$ (Bend) & 1052145 & 1050870 & 0.12 \\
\hline & $\omega_{2}^{(3)}(\mathrm{Th})$ & 1186447 & 1182760 & 0.31 \\
\hline & $\omega_{4}^{(2)}(\mathrm{Th})$ & 1218605 & 1201120 & 1.46 \\
\hline
\end{tabular}
two-layer FGP laminate $(S=5)$.

between the present and ABAQUS results is 1.25, whatever the values of the material gradient index.

The effect of electric boundary conditions, namely $\mathrm{OC}$ or $\mathrm{CC}$, on the natural frequencies of the FGP laminates is illustrated in Table 4 . Compared with the results obtained in Table 3 , one can observe that the OC electrical boundary conditions lead to slightly higher natural frequencies regardless of the material gradient index. This effect, which is related to the piezoelectric coupling, is very well-captured by the present exact state-space formulation. The higher modes of vibration are more sensitive to the electric boundary conditions on the top and bottom planes of the FGP laminate than the lower modes. For example, for $a=1$, the thickness mode natural frequency $\omega_{4}^{(2)}$ changes by $29543 \mathrm{~Hz}$ depending on whether it is electrically closed or open. In comparison, the fundamental frequency $\omega_{1}^{(1)}$ changes only by $602 \mathrm{~Hz}$.

Figure 6 shows through-the-thickness variations 


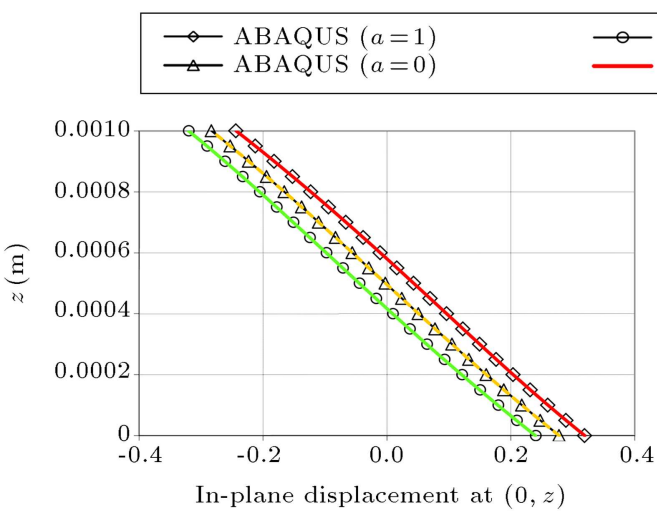

$\operatorname{ABAQUS}(a=-1)$ Present $(a=1)$

- - - Present $(a=0)$
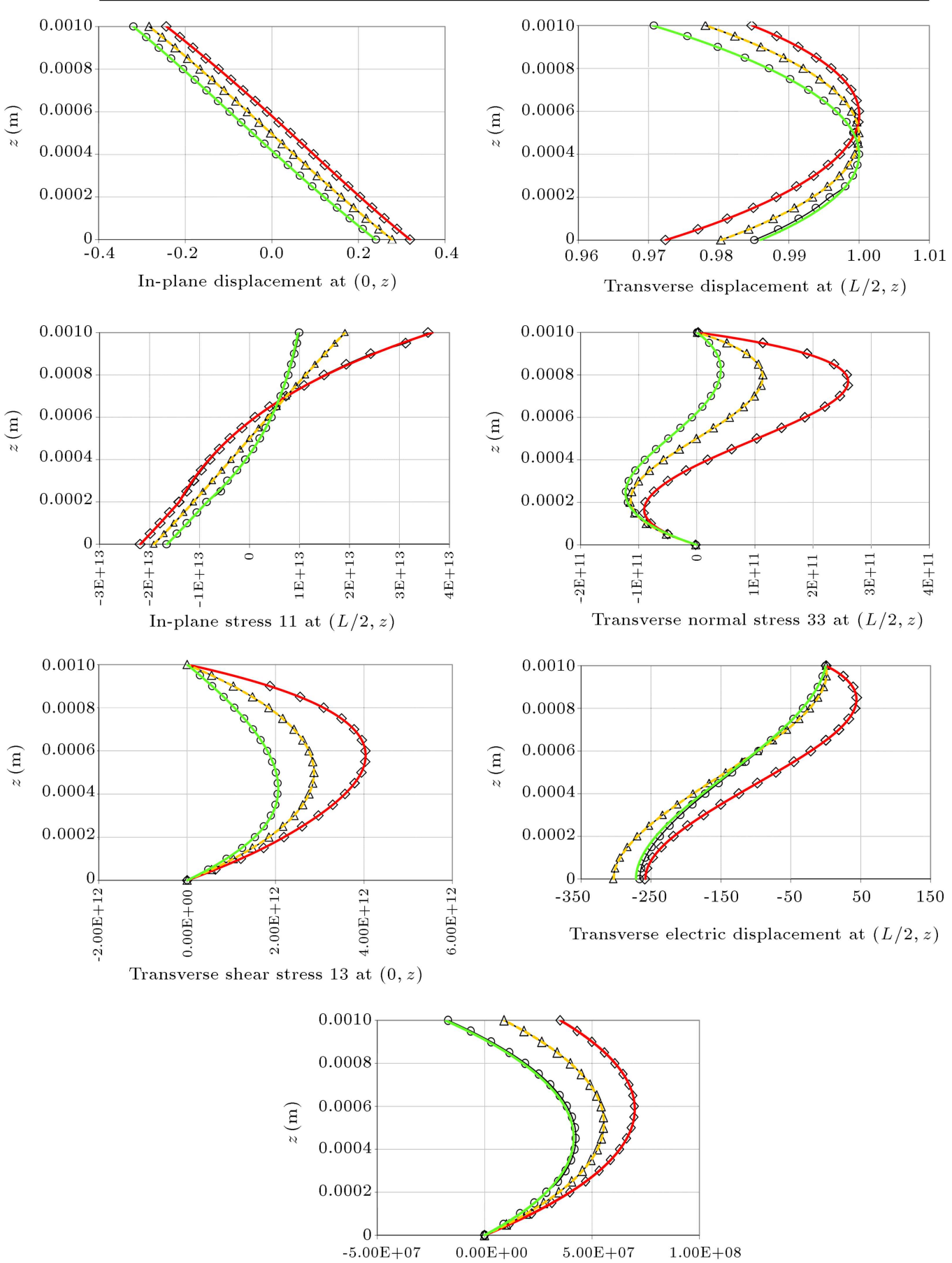

Induced electric potential at $(L / 2, z)$

Figure 6. Distributions of $\tilde{u}_{1}, \tilde{u}_{3}, \tilde{\sigma}_{11}, \tilde{\sigma}_{33}, \tilde{\sigma}_{13}, \tilde{D}_{3}$, and $\tilde{\varphi}$ along the thickness of the simply supported two-layer FGP plate in the first bending mode (open circuit conditions); $S=5$.

of modal entities $\tilde{u}_{1}, \tilde{u}_{3}, \tilde{\sigma}_{11}, \tilde{\sigma}_{33}, \tilde{\sigma}_{13}, \tilde{D}_{3}$, and $\tilde{\varphi}$ at the different sections of the thick two-layer FGP laminate in the first bending mode. For the material gradient index, three different values of 1,0 , and -1 are considered. The top plane of the graded laminate is electrically open while its bottom plane is grounded
(OC). The modal entities are normalized as follows:

$$
\begin{aligned}
& \left(\tilde{u}_{1}, \tilde{u}_{3}, \tilde{\sigma}_{11}, \tilde{\sigma}_{33}, \tilde{\sigma}_{13}, \tilde{D}_{3}, \tilde{\varphi}\right) \\
& \quad=\left(u_{1}, u_{3}, \sigma_{11}, \sigma_{33}, \sigma_{13}, D_{3}, \varphi\right) / \max \left(u_{1}, u_{3}\right) .
\end{aligned}
$$

The results have been compared with $2 \mathrm{D}$ finite element 
results. It can be observed from Figure 6 that the distributions of modal entities obtained from the present exact formulation are in excellent agreement with the ABAQUS results. Figure 6 also shows that the gradient index $a$ influences the distribution of modal stresses, displacements, electric potential, and transverse electric displacement in different degrees. The value of $a$ has little influence on the distribution of the modal displacement components and the transverse electric displacement; however, it influences the distribution of the induced electric potential and stress components, effectively. For $a=1$, the maximal absolute value of $\tilde{\varphi}$ is $64 \%$ larger than that of $a=-1$. The maximal absolute value of $\tilde{\sigma}_{13}$ in the FGP laminate with $a=1$ is 2 times as large as that with $a=-1$. This value for $\tilde{\sigma}_{33}$ is 6.35 .

In order to see the effect of electric boundary conditions on the modal entities, the distributions of $\tilde{u}_{1}$, $\tilde{u}_{3}, \tilde{D}_{3}$ and $\tilde{\varphi}$ along the thickness of the thick two-layer FGP laminate with $\mathrm{CC}$ electric boundary conditions in the first bending mode are depicted in Figure 7. It is seen from Figure 7 that the electric boundary conditions have little influence on the distribution of the modal displacement components. They also have little influence on the distribution of the modal stress components. For the sake of brevity, the corresponding results have not been shown here. However, electric boundary conditions influence the distribution of the modal electric potential and the transverse electric displacement, effectively.

\subsection{Example 4}

In order to assess the accuracy of the present 3D solution for dynamic analysis of FGP laminates with high values of gradient indices, free vibration of a single-layer FGP strip with $a=10$ and $a=-10$ is considered in this example. The thickness of the considered strip is $h=0.001 \mathrm{~m}$ and its length-tothickness ratio is assumed to be $S=5$. Boundary conditions, geometry, and other material properties of the FGP strip of the present example are the same as those of Example 2. The first 10 natural frequencies of the FGP strip are shown in Table 5. The assumed electric boundary condition is OC. In this table, the obtained numerical results of the present example have been compared with the results obtained from 2D finite element analysis. It can be observed that the present results are in excellent agreement with $2 \mathrm{D}$ finite element results. The maximum percent of discrepancy between the present and ABAQUS results is 0.43 .

\subsection{Example 5}

As a final example, the steady-state response of a twolayer FGP laminate with length-to-thickness ratio due to harmonic mechanical and electrical loads is studied in this section. Boundary conditions, geometry, and
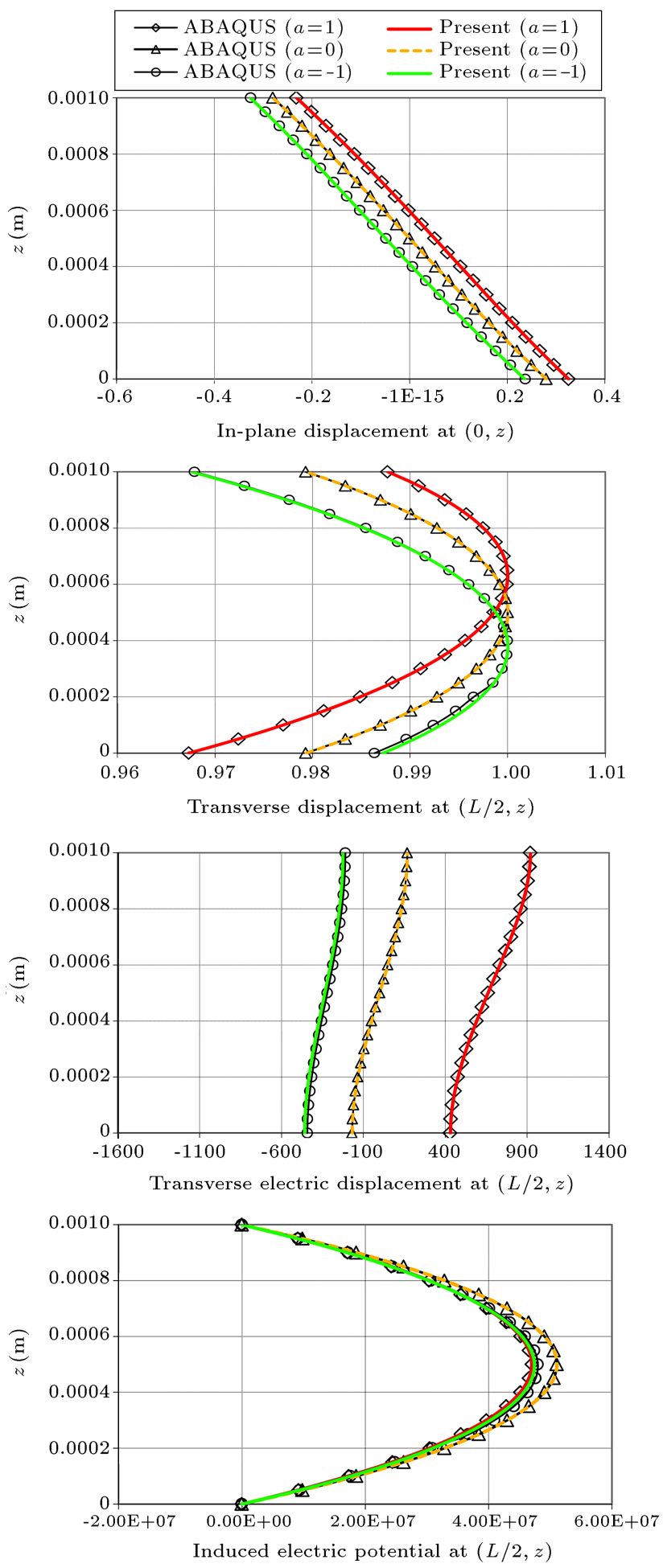

Figure 7. Through-the-thickness distributions of $\tilde{u}_{1}, \tilde{u}_{3}$, $\tilde{D}_{3}$, and $\tilde{\varphi}$ in the two-layer FGP plate in the first bending mode (close circuit conditions); $S=5$.

material properties of the two-layer FGP laminate of the present example are the same as those of Example 3. The top plane of the FGP laminate was first applied under the action of the harmonic distributed force $\sigma_{33}\left(x_{1}, h, t\right)=q_{0}(\sin 4000 \pi)\left(\sin \pi x_{1} / L\right)$. The 
Table 5. Open circuit natural frequencies of the single-layer FGP strip with high values of the material gradient index $(S=5)$.

\begin{tabular}{|c|c|c|c|c|}
\hline \multirow{2}{*}{$\begin{array}{l}\text { Material } \\
\text { gradient } \\
\text { index }\end{array}$} & \multicolumn{4}{|c|}{ Natural frequencies $(\mathrm{Hz})$} \\
\hline & Mode & Present & ABAQUS & $\begin{array}{c}\text { Difference } \\
(\%)\end{array}$ \\
\hline \multirow[t]{10}{*}{$a=10$} & $\omega_{1}^{(1)}$ (Bend) & 23185 & 23180 & 0.02 \\
\hline & $\omega_{2}^{(1)}($ Bend $)$ & 88205 & 88124 & 0.09 \\
\hline & $\omega_{3}^{(1)}($ Bend $)$ & 185329 & 185009 & 0.17 \\
\hline & $\omega_{4}^{(1)}($ Bend $)$ & 305408 & 304654 & 0.25 \\
\hline & $\omega_{1}^{(2)}(\mathrm{Th})$ & 378281 & 378279 & 0.00 \\
\hline & $\omega_{5}^{(1)}($ Bend $)$ & 441913 & 440548 & 0.31 \\
\hline & $\omega_{6}^{(1)}$ (Bend) & 590511 & 588388 & 0.36 \\
\hline & $\omega_{7}^{(1)}($ Bend $)$ & 748283 & 745288 & 0.40 \\
\hline & $\omega_{2}^{(2)}(\mathrm{Th})$ & 754580 & 754576 & 0.00 \\
\hline & $\omega_{8}^{(1)}$ (Bend) & 913184 & 909237 & 0.43 \\
\hline \multirow[t]{10}{*}{$a=-10$} & $\omega_{1}^{(1)}$ (Bend) & 23224 & 23220 & 0.02 \\
\hline & $\omega_{2}^{(1)}($ Bend $)$ & 87678 & 87615 & 0.07 \\
\hline & $\omega_{3}^{(1)}$ (Bend) & 182677 & 182441 & 0.13 \\
\hline & $\omega_{4}^{(1)}$ (Bend) & 298907 & 298391 & 0.17 \\
\hline & $\omega_{1}^{(2)}(\mathrm{Th})$ & 378213 & 378206 & 0.00 \\
\hline & $\omega_{5}^{(1)}($ Bend $)$ & 430202 & 429339 & 0.20 \\
\hline & $\omega_{6}^{(1)}($ Bend $)$ & 572699 & 571458 & 0.22 \\
\hline & $\omega_{7}^{(1)}($ Bend $)$ & 723877 & 722254 & 0.22 \\
\hline & $\omega_{2}^{(2)}(\mathrm{Th})$ & 753494 & 753442 & 0.01 \\
\hline & $\omega_{8}^{(1)}$ (Bend) & 881985 & 879998 & 0.23 \\
\hline
\end{tabular}

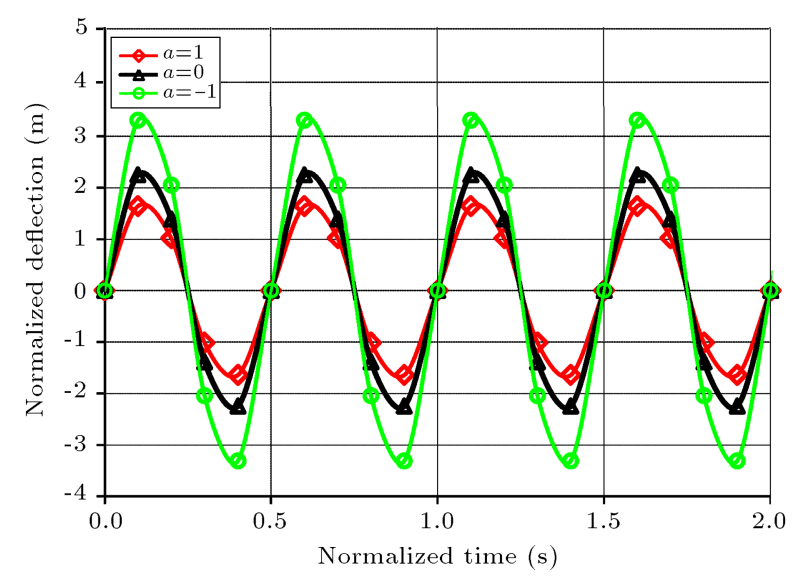

Figure 8. Steady-state response of the two-layer FGP plate subjected to a harmonic distributed mechanical force; central deflection.

top and bottom planes of the laminate are assumed to be grounded. The time history response of the normalized central deflection of the FGP laminate is shown in Figure 8 for three values of the material gradient index $a=-1, a=0$, and $a=1$. The normalized values of deflection and time are given as

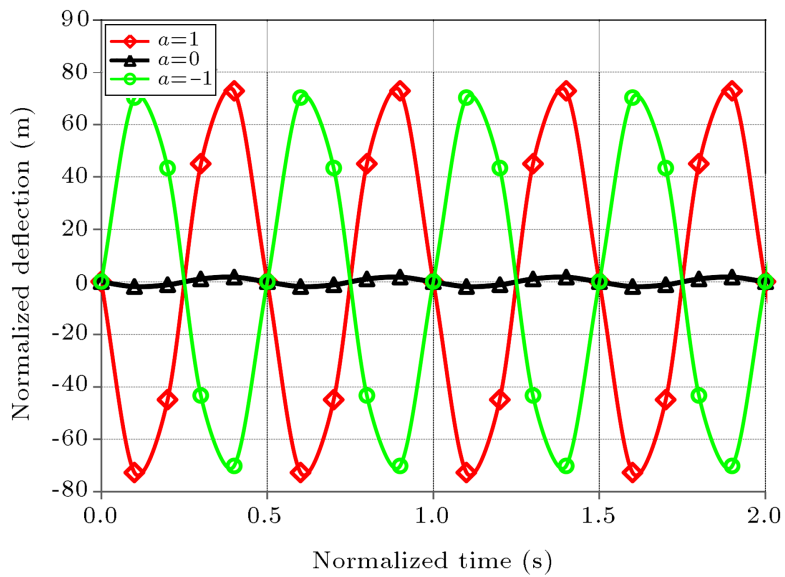

Figure 9. Central deflection of the two-layer FGP plate subjected to a harmonic distributed electric potential.

$\bar{u}_{3}=u_{3} \times 10^{10} / q_{0}$ and $\bar{t}=t \times 10^{3}$. It can be observed from Figure 8 that the deflection of the laminate made of soft gradient materials is higher than that of the laminate made of hard gradient materials. For $a=-1$, the peak deflection of the FGP laminate is 2.02 times as large as that for $a=1$. Due to the fact that the electromechanical stiffness of a graded laminate made of hard piezoelectric materials is higher than that of a soft one, such behaviors are expected.

In the next case, the harmonic distributed electric potential $\varphi\left(x_{1}, h, t\right)=\varphi_{0}(\sin 4000 \pi)\left(\sin \pi x_{1} / L\right)$ is applied on the top plane of the FGP laminate. The bottom plane of the laminate is assumed to be grounded. The normalized central deflection $\left(\bar{u}_{3}=\right.$ $\left.u_{3} \times 10^{10} / \varphi_{0}\right)$ of the FGP laminate with respect to normalized time $\left(\bar{t}=t \times 10^{3}\right)$ is shown in Figure 9 for different values of the material gradient index. The depicted graphs in Figure 9 reveal this fact that under a similar electric force, the transverse deflection of an FGP laminate is much higher than that of a monomorph one $(a=0)$. This example shows that by employing the FGP actuators, it is possible to generate larger deflections in the host structures.

\section{Conclusions}

In the present paper, a Peano series solution is employed to investigate free vibration of FGP laminates. The presented series solution exactly satisfies the 3D theory equations of piezoelasticity. Unlike the available reported methods which consider the FGP layer as a number of homogeneous sub-layers, the present formulation considers FGP layers as a transversely nonhomogeneous material. For validation, some comparisons have been made with the results obtained from the coupled 2D finite element analysis. Excellent agreements have been found between the numerical results obtained from the present exact formulation and those obtained from the $2 \mathrm{D}$ finite element analysis. 
Through different examples, the influences of different functionally gradient material properties and different electric boundary conditions on the natural frequencies, modal entities, and mode shapes of the FGP laminates have been studied. The obtained numerical results of the present study give a comprehensive insight into the vibration behavior of the FGP laminates. Moreover, the presented numerical results are new and can be used by researchers as a benchmark for validating different FGP beam/plate theories.

\section{References}

1. Beheshti-Aval, S.B. and Lezgy-Nazargah, M. "A finite element model for composite beams with piezoelectric layers using a sinus model", J. Mech., 26(2), pp. 249258 (2010).

2. Heyliger, P.R. and Saravanos, D.A. "Coupled discretelayer finite elements for laminated piezoelectric plates", Commun. Numer. Methods Eng., 10(12), pp. 971-981 (1994).

3. Saravanos, D.A. and Heyliger, P.R. "Coupled layerwise analysis of composite beams with embedded piezoelectric sensors and actuators", J. Intell. Mater. Syst. Struct., 6, pp. 350-363 (1995).

4. Tzou, H.S. and Gadre, M. "Theoretical analysis of a multi-layered thin shell coupled with piezoelectric shell actuators for distributed vibration controls", J. Sound Vib., 132, pp. 433-450 (1989).

5. Beheshti-Aval, S.B. and Lezgy-Nazargah, M. "Assessment of velocity-acceleration feedback in optimal control of smart piezoelectric beams", Smart. Struct. Syst., 6(8), pp. 921-938 (2010).

6. Beheshti-Aval, S.B., Lezgy-Nazargah, M., Vidal, P. and Polit, O. "A refined sinus finite element model for the analysis of piezoelectric laminated beams", $J$. Intell. Mater. Syst. Struct., 22, pp. 203-219 (2011).

7. Beheshti-Aval, S.B. and Lezgy-Nazargah, M. "A coupled refined high-order global-local theory and finite element model for static electromechanical response of smart multilayered/sandwich beams", Arch. Appl. Mech., 82(12), pp. 1709-1752 (2012).

8. Beheshti-Aval, S.B. and Lezgy-Nazargah, M. "Coupled refined layerwise theory for dynamic free and forced response of piezoelectric laminated composite and sandwich beams', Meccanica, 48(6), pp. 1479-1500 (2013).

9. Beheshti-Aval, S.B., Shahvaghar-Asl, S., Lezgy-Nazargah, M. and Noori, M. "A finite element model based on coupled refined high-order global-local theory for static electromechanical analysis of embedded shear mode piezoelectric sandwich composite beams", Thin Walled Struct., 72, pp. 139-163 (2013).

10. Niezrecki, C., Brei, D., Balakrishnan, S. and Moskalik, A. "Piezoelectric actuation: State of the art", Shock Vib. Dig., 33(4), pp. 269-280 (2001).
11. Ray, M.C. "Micromechanics of piezoelectric composites with improved effective piezoelectric constant", Int. J. Mech. Mater. Des., 3, pp. 361-371 (2006).

12. Lezgy-Nazargah, M. "A micromechanics model for effective coupled thermo-electro-elastic properties of macro fiber composites with interdigitated electrodes", J. Mech., 31(2), pp. 183-199 (2015).

13. Doroushi, A., Eslami, M.R. and Komeili, A. "Vibration analysis and transient response of an FGPM Beam under thermo-electro-mechanical loads using higherorder shear deformation theory", J. Intell. Mater. Syst. Struct., 22, pp. 231-243 (2011).

14. Lezgy-Nazargah, M. and Farahbakhsh, M. "Optimum material gradient composition for the functionally graded piezoelectric beams", Int. J. Eng. Sci. Tech., 5(4), pp. 80-99 (2013).

15. Lezgy-Nazargah, M., Vidal, P. and Polit, O. "An efficient finite element model for static and dynamic analyses of functionally graded piezoelectric beams", Compos. Struct., 104, pp. 71-84 (2013).

16. Zhu, X.H. and Meng, Z.Y. "Operational principle, fabrication and displacement characteristic of a functionally gradient piezoelectric ceramic actuator", Sens. Actuators A., 48, pp. 169-176 (1995).

17. Wu, C.C.M., Kahn, M. and Moy, W. "Piezoelectric ceramics with functional gradients: A new application in material design", J. Am. Ceram. Soc., 79, pp. 809812 (1996).

18. Yang, J. and Xiang, H.J. "Thermo-electro-mechanical characteristics of functionally graded piezoelectric actuators", Smart Mater. Struct., 16, pp. 784-797 (2007).

19. Behjat, B., Salehi, M., Sadighi, M., Armin, A. and Abbasi, M. "Static, dynamic, and free vibration analysis of functionally graded piezoelectric panels using finite element method", J. Intell. Mater. Syst. Struct., 20, pp. 1635-1646 (2009).

20. Behjat, B., Salehi, M., Armin, A., Sadighi, M. and Abbasi, M. "Static and dynamic analysis of functionally graded piezoelectric plates under mechanical and electrical loading", Scientia Iranica. Transactions B: Mech. Eng., 18(4), pp. 986-994 (2011).

21. Wu, X.H., Chen, C.Q. and Shen, Y.P. "A high order theory for functionally graded piezoelectric shells", Int. J. Solids Struct., 39, pp. 5325-5344 (2002).

22. Brischetto, S. and Carrera, E. "Refined 2D models for the analysis of functionally graded piezoelectric plates", J. Intell. Mater. Syst. Struct., 20, pp. 17831797 (2009).

23. Lee, H.J. "Layerwise laminate analysis of functionally graded piezoelectric bimorph beams", J. Intell. Mater. Syst. Struct., 16, pp. 365-371 (2005).

24. Lu, P., Lee, H.P. and Lu, C. "An exact solution for functionally graded piezoelectric laminates in cylindrical bending", Int. J. Mech. Sci., 47, pp. 437-458 (2005). 
25. Reddy, J.N. and Cheng, Z.Q. "Three-dimensional solutions of smart functionally graded plates", $A S M E$ J. Appl. Mech., 68, pp. 234-241 (2001).

26. Liu, G.R. and Tani, J. "Surface waves in functionally gradient piezoelectric plates", ASME J. Vib. Acoust., 116, pp. 440-448 (1994).

27. Chen, W.Q. and Ding, H.J. "On free vibration of a functionally graded piezoelectric rectangular plate", Acta Mech., 153, pp. 207-216 (2002).

28. Li, Y. and Shi, Z. "Free vibration of a functionally graded piezoelectric beam via state-space based differential quadrature", Compos. Struct., 87, pp. 257-264 (2009).

29. Zhong, Z. and Shang, E.T. "Three-dimensional exact analysis of a simply supported functionally gradient piezoelectric plate", Int. J. Solids Struct., 40, pp. 5335-5352 (2003).

30. Lu, P., Lee, H.P. and Lu, C. "Exact solutions for simply supported functionally graded piezoelectric laminates by Stroh-like formalism", Comput. Struct., 72, pp. 352-363 (2006).

31. Liu, T.T. and Shi, Z.F. "Bending behavior of functionally gradient piezoelectric cantilever", Ferroelectrics., 308, pp. 43-51 (2004).

32. Shi, Z.F. and Chen, Y. "Functionally graded piezoelectric cantilever beam under load", Arch. Appl. Mech., 74, pp. 237-247 (2004).

33. Xiang, H.J. and Shi, Z.F. "Static analysis for functionally graded piezoelectric actuators or sensors under a combined electro-thermal load", Eur. J. Mech. A Solids, 28, pp. 338-346 (2009).

34. Lim, C.W. and He, L.H. "Exact solution of a compositionally graded piezoelectric layer under uniform stretch, bending and twisting", Int. J. Mech. Sci., 43, pp. 2479-2492 (2001).

35. Lezgy-Nazargah, M. "A three-dimensional exact statespace solution for cylindrical bending of continuously non-homogenous piezoelectric laminated plates with arbitrary gradient composition", Arch. Mech., 67(1), pp. 25-51 (2015).

36. Heyliger, P. and Brooks, S. "Free vibration of for piezoelectric laminates in cylindrical bending", Int. J. Solid Struct., 32(20), pp. 2945-2960 (1995).

37. Gantmakher, F.R., The Theory of Matrices, Chelsea, New York (1959).

38. Pease, M.C., Methods of Matrix Algebra, Academic Press, New York (1965).

39. Alshits, V.I., Kirchner, H.O.K. and Maugin, G.A. "Elasticity of multilayers: properties of the propagator matrix and some applications", Math. \& Mech. Sol., 6(5), pp. 481-502 (2001).

\section{Biography}

Mojtaba Lezgy-Nazargah received the BS degree in Civil Engineering from Shahrood University of Technology, Shahrood, Iran, in 2006. He received his MS and $\mathrm{PhD}$ degrees in Civil and Structural Engineering from K.N. Toosi University of Technology, Tehran, Iran, in 2008 and 2011, respectively. He has been working as Assistant Professor in the Civil Engineering Department at Hakim Sabzevari University, Sabzevar, Iran, since 2011. His major research interests include computational mechanics, active vibration control of structures, smart materials and structures, laminated composite structures, and nonlinear analysis of steel and reinforced concrete structures. He has published more than 18 papers in the international journals. He has also written a book on design of reinforced concrete structures in Persian. Dr. Lezgy-Nazargah has supervised $16 \mathrm{MS}$ research works in his research areas. He teaches courses on Static, Mechanics of Materials, Finite Element Analysis, Theory of Elasticity, Plates and Shells, and Design of Reinforced Concrete Structures. 